\title{
Evaluation of snow cover and snow depth on the Qinghai-Tibetan Plateau derived from passive microwave remote sensing
}

\author{
Liyun Dai ${ }^{1,2}$, Tao Che ${ }^{1,3}$, Yongjian Ding ${ }^{4}$, and Xiaohua Hao ${ }^{1}$ \\ ${ }^{1}$ Key Laboratory of Remote Sensing of Gansu Province, Heihe Remote Sensing Experimental Research Station, Cold and \\ Arid Regions Environmental and Engineering Research Institute, Chinese Academy of Sciences, Lanzhou 730000, China \\ ${ }^{2}$ Jiangsu Center for Collaborative Innovation in Geographical Information Resource Development and Application, \\ Nanjing 21003, China \\ ${ }^{3}$ Center for Excellence in Tibetan Plateau Earth Sciences, Chinese Academy of Sciences, Beijing 100101, China \\ ${ }^{4}$ State Key Laboratory of Cryospheric Sciences, Cold and Arid Regions Environmental and Engineering Research Institute, \\ Chinese Academy of Sciences, Lanzhou 730000, China \\ Correspondence to: Tao Che (chetao@1zb.ac.cn)
}

Received: 11 November 2016 - Discussion started: 19 December 2016

Revised: 10 March 2017 - Accepted: 14 July 2017 - Published: 23 August 2017

\begin{abstract}
Snow cover on the Qinghai-Tibetan Plateau (QTP) plays a significant role in the global climate system and is an important water resource for rivers in the high-elevation region of Asia. At present, passive microwave (PMW) remote sensing data are the only efficient way to monitor temporal and spatial variations in snow depth at large scale. However, existing snow depth products show the largest uncertainties across the QTP. In this study, MODIS fractional snow cover product, point, line and intense sampling data are synthesized to evaluate the accuracy of snow cover and snow depth derived from PMW remote sensing data and to analyze the possible causes of uncertainties. The results show that the accuracy of snow cover extents varies spatially and depends on the fraction of snow cover. Based on the assumption that grids with MODIS snow cover fraction $>10 \%$ are regarded as snow cover, the overall accuracy in snow cover is $66.7 \%$, overestimation error is $56.1 \%$, underestimation error is $21.1 \%$, commission error is $27.6 \%$ and omission error is $47.4 \%$. The commission and overestimation errors of snow cover primarily occur in the northwest and southeast areas with low ground temperature. Omission error primarily occurs in cold desert areas with shallow snow, and underestimation error mainly occurs in glacier and lake areas. With the increase of snow cover fraction, the overestimation error decreases and the omission error increases. A comparison between snow depths measured in field experiments, measured at meteorological stations and estimated
\end{abstract}

across the QTP shows that agreement between observation and retrieval improves with an increasing number of observation points in a PMW grid. The misclassification and errors between observed and retrieved snow depth are associated with the relatively coarse resolution of PMW remote sensing, ground temperature, snow characteristics and topography. To accurately understand the variation in snow depth across the QTP, new algorithms should be developed to retrieve snow depth with higher spatial resolution and should consider the variation in brightness temperatures at different frequencies emitted from ground with changing ground features.

\section{Introduction}

The Qinghai-Tibetan Plateau (QTP) is considered the third pole of the world and the Asian water tower (Kang et al., 2010; Wu and Qian, 2003; Wang et al., 2015; Immerzeel et al., 2010; Xu et al., 2008). Snow cover over it plays a significant role in the climate change and hydrological circle. Due to its importance regionally and globally and evident change (Shi and Wang, 2015; Lü et al., 2008; Zhang et al., 2004), more attention should be paid to the snow cover variability across the QTP. Monitoring snow cover variability requires reliable snow depth and snow cover data.

Traditional station observation is used to monitor interannual variation of snow depth at local or regional scales. Inter- 
annual changes in snow cover and depth in Russia were analyzed using snow depths observed at 856 stations (Bulygina et al., 2009). Zhong et al. (2014) used station observation to analyze the snow density of Eurasian region. It was also used for long time series analysis due to its long history (Gafurov et al., 2015). However, meteorological station data do not always represent the snow status of a region, especially in regions with few stations such as the QTP, although there are some studies that have reported spatiotemporal variation across the QTP using an interpolation method based on meteorological stations (Wang et al., 2009; You et al., 2011). In the absence of a large, distributed network of meteorological stations, remote sensing becomes a necessary technique.

Optical remote sensing can be used to identify snow cover extent accurately using the normalized difference of snow index (NDSI) method due to its high reflectance in the optical band and low reflectance in the near-infrared band (Hall et al., 2002; Hall and Riggs, 2007). However, the drawback of optical remote sensing is that clouds mask snow data on most the days during the snow season. Therefore, 8-day and 16-day composite snow cover products are produced to eliminate cloud cover (Hall et al., 2002; Hall and Riggs, 2007). Daily cloud-free snow cover products were also produced using temporal or spatial interpolation algorithms (Tang et al., 2013; Hall et al., 2010; Gafurov and Bárdossy, 2009; Parajka et al., 2010). However, for the strong spatial heterogeneity and rapid snow cover changes across the QTP, interpolation algorithms do not work under conditions of continuous multi-day cloud cover or for large areas. Therefore, in the cloud-covered areas, snow cover derived from passive microwave (PMW) remote sensing, which is independent of sunlight, has been used to supplement optical remote sensing (Liang et al., 2008; Gao et al., 2012; Deng et al., 2015). The data from the combination of these two techniques provide information masked by clouds and improves the temporal resolution of snow cover products. Many combined snow cover products have been used in climate change and hydrological analysis (Barnett et al., 2005; Wang et al., 2015; Brown and Robinson, 2011; Choi et al., 2010). However, the accuracy of snow cover from PMW directly influences the accuracy of the combined snow cover product. In addition, although optical remote sensing is an efficient way to monitor spatial snow cover with high resolution, it cannot penetrate snowpack and obtain snow depth.

PMW is the only efficient way to monitor the spatial and temporal variation of snow depth. It is used to identify snow cover based on the volume scattering of snow particles. Brightness temperature emitted from the ground goes through snowpack and is scattered by snow particles. Furthermore, the scatter intensity at low frequency is weaker than that at high frequency, and the difference increases with number of snow particles. Therefore, regional and local snow depths have been retrieved based on the microwave spectral gradient method (Kelly et al., 2003; Pullianen, 2006; Dai et al., 2012; Jiang et al., 2014), and these snow depth products have been widely used in climate change and vegetation variation, frozen soil detection and hydrological cycle studies (Gao et al., 2012; Yu et al., 2013; Xu et al., 2009; Immerzeel et al., 2009).

However, there are uncertainties with these snow depth products, and some assessments had been performed on them. The NASA snow water equivalent product derived from Advanced Microwave Scanning Radiometer for Earth Observing System (AMSR-E) generally tends to underestimate snow depth in North America (Tedesco and Narvekar, 2010) when compared with World Meteorological Organization (WMO) and Snow Data Assimilation System (SNODAS) but overestimate in northwest and northeast of China (Dai et al., 2012; Che et al., 2016) when compared with meteorological station and field work observations. These authors pointed out that the errors primarily came from the spatiotemporal variability of grain size and forest cover. It was because of the strong influence of grain size that mass investigation of snow characteristics were performed to obtain the a priori information of snow characteristics in northwest and northeast China to improve the simulation of brightness temperature and retrieval accuracy of snow depth. Some research assimilated snow depth observed at stations or built a local empirical relationship between snow depth observations and spectral gradients to improve the snow depth retrieval accuracy in some regions (Dai et al., 2012; Che et al., 2016, 2008; Pullianen, 2006). In order to reduce the influence of forest, forest transmissivities at different frequencies were absorbed in the algorithm or the special equations were built between snow depth and brightness temperature difference (TBD) at different types of forest to estimate snow depth more accurately at forest areas (Che et al., 2016; Pullianen, 2006). However, uncertainties still exist for the snow depth over QTP except regarding grain size and forest. Based on existing research, the snow cover over the QTP was also overestimated compared with the optical snow extent products (Frei et al., 2012; Armstrong and Brodzik, 2002). Across the QTP, meteorological stations are rare and primarily distributed in the valley with low elevation. Snow depth observed at these stations does not represent the snow status of the grid they are located on, and so it is unclear whether data assimilation and an empirical equation will work to improve snow depth accuracy. It has also been reported that snow cover across the QTP is overestimated by PMW algorithms compared to IMS snow cover products (Ramsay, 1998), which was caused by the high elevation with a thinner atmosphere (Savoie et al., 2009). Compared with meteorological station observation, AMSR-E SWE also presented overestimation (Yang et al., 2015). However, Smith and Bookhagen (2016) thought Tibet lacks an extensive and reliable ground-weather station network; therefore they did not rely on in situ data but focused on the factors reducing the reliability of SWE estimates from satellite-based PMW data by comparing different satellite sensors. They found that satellite look angle and elevation showed very little influence 
on SWE variability. Thus, it seemed that general overestimation was undoubted for the QTP, but at present there is no definitive answer to what the causes are and where the overestimates occur over the QTP.

Therefore, the purposes of this study are to provide a reliable evaluation or assessment of the ability of passive microwave to detect snow cover and snow depth across the QTP using MODIS snow cover product and in situ observation data, analyze the cause of uncertainties and provide reference for the use of PMW snow depth data and improvements to the retrieval algorithm for snow depth across the QTP.

\section{Data}

\subsection{MODIS snow cover fraction (SCF)}

The Terra/Aqua MODIS Level 3, $500 \mathrm{~m}$ daily fractional snow cover products (MOD10A1 and MYD10A1) were obtained from the National Snow and Ice Data Center (NSIDC) from 1 January 2003 to 31 December 2014 (Riggs et al., 2006). These products derived from MODIS were generated based on the regression relationship between NDSI and SCF. The relationship equation is $\mathrm{SCF}=a+b^{*}$ NDSI, and the coefficients $a$ and $b$ and NDSI vary with sensors. Coefficients $a$ and $b$ are -0.01 and 1.45 for MODA1 and -0.64 and 1.91 for MYDA, respectively. NDSI is the function of band 4 and band 6 for Terra (MODA1) and band 4 and band 7 for Aqua (MYDA1) (Salomonson and Appel, 2004, 2006). To develop a relationship between NDSI and SCF within a MODIS $500 \mathrm{~m}$ pixel, it was necessary to utilize a source of ground truth. In this algorithm, several Landsat scenes covering a wide variety of snow cover conditions were selected, and every $30 \mathrm{~m}$ pixel of Landsat scene was classified as snow or no snow. The number of snow cover pixels for Landsat in a MODIS grid and the total number of Landsat pixels in a MODIS grid were calculated. The ratio of them was the ground truth of SCF. When the derived snow cover fractions were compared to Landsat-7 Enhanced Thematic Mapper ground-truth observations covering a substantial range of snow cover conditions, the correlation coefficients were near 0.9 and the RMSE were near 0.10 (Salomonson and Appel, 2006).

\subsection{Passive microwave brightness temperature and snow depth product}

The AMSR-E, which measures 12 bands of six frequencies, was operated from the NASA EOS Aqua Satellite and provided global passive microwave measurements of the earth from June 2002 to October 2010. To provide consistency of different frequencies with different footprints, the brightness temperature was resampled to an equal-area scalable earth grid (EASE-Grid) with a resolution of $25 \mathrm{~km}$. In this study, the brightness temperature at $18.7 \mathrm{GHz}, 36.5 \mathrm{GHz}$ at both vertical and horizontal polarization $\left(\mathrm{TB}_{18 \mathrm{H}}, \mathrm{TB}_{18 \mathrm{~V}}\right.$,
$\left.\mathrm{TB}_{36 \mathrm{H}}, \mathrm{TB}_{36 \mathrm{~V}}\right), 23.8 \mathrm{GHz}$, and $89.0 \mathrm{GHz}$ at vertical polarization $\left(\mathrm{TB}_{23 \mathrm{~V}}, \mathrm{~TB}_{89 \mathrm{~V}}\right)$ from 1 January 2003 to 31 December 2008 was used to identify snow cover and derive snow depth across the QTP.

The Advanced Microwave Scanning Radiometer-2 (AMSR2) carried on the Global Change Observation Mission (GCOM) was launched on 18 May 2012 (Imaoka et al., 2010) and provided brightness temperature from 3 July 2012. The AMSR2 sensor was the continuation of AMSR-E and has the same channels as the AMSR-E but a slightly smaller footprint. The AMSR2 brightness temperatures from November 2013 to March 2014 were used to derive the snow depth in the field experiment areas. In order to avoid the influence of liquid water, the descending orbit data were used, and the snowpack was set as wet when the brightness temperature at $36 \mathrm{GHz}$ for vertical polarization was more than $265 \mathrm{~K}$.

The core principle of retrieving snow depth from passive microwave remote sensing data is that snow particles scatter the microwave signals emitted from the ground, and the brightness temperature of ground declines as it crosses the snowpack. The higher the frequency, the greater the radiation scatters, and more snow particles lead to a larger brightness temperature gradient. Therefore, the spectral gradient, namely the TBD between lower frequency and higher frequency, is used to derive snow depth. Based on modeling and observation, the $18 \mathrm{GHz}$ ( $\mathrm{K}$ band) and $36 \mathrm{GHz}$ (Ka band) are the best frequencies for deriving snow depth (Chang et al., 1987; Kelly et al., 2003). The TBD between these two frequencies has a good relationship with snow water equivalent.

However, frozen soil and cold desert also scatter radiation, and their existence leads to a positive TBD (Grody and Basist, 1996). Therefore, before retrieving snow depth, snow cover must be identified from other scattering sources. In this study, a modified global snow identification method is used to retrieve snow cover using AMSR-E brightness temperature. The criteria are described as follows.

$$
\begin{aligned}
& \text { Cold desert: } \mathrm{TB}_{18 \mathrm{~V}}-\mathrm{TB}_{18 \mathrm{H}}>=18(\mathrm{~K}) \text { and } \\
& \mathrm{TB}_{18 \mathrm{~V}}-\mathrm{TB}_{36 \mathrm{~V}}<=10(\mathrm{~K}) \text { and } \\
& \mathrm{TB}_{36 \mathrm{~V}}-\mathrm{TB}_{85 \mathrm{~V}}<=10(\mathrm{~K}) \\
& \text { Frozen soil: } \mathrm{TB}_{18 \mathrm{~V}}-\mathrm{TB}_{18 \mathrm{H}}>=8(\mathrm{~K}) \text { and } \\
& \mathrm{TB}_{18 \mathrm{~V}}-\mathrm{TB}_{36 \mathrm{~V}}<=2(\mathrm{~K}) \text { and } \\
& \mathrm{TB}_{36 \mathrm{~V}}-\mathrm{TB}_{85 \mathrm{~V}}<=6(\mathrm{~K})
\end{aligned}
$$

Snow depth $(\mathrm{cm})=0.7 \times\left(\mathrm{TB}_{18 \mathrm{H}}-\mathrm{TB}_{36 \mathrm{H}}-5\right) /$

$$
(1-0.5 f)+\text { offset }
$$

Offset was monthly data used to decrease the influence of snow characteristics growth. They are $-4.18,-3.58,-0.29$, 2.15, 3.31 and 3.8 for October, November, December, January, February, March and April, respectively (Che et al., 2008). These criteria were developed based SSM/I (Grody and Basist, 1996). Based on the inter-sensor comparison between SSM/I and AMSR-E in Dai and Che (2009) and be- 


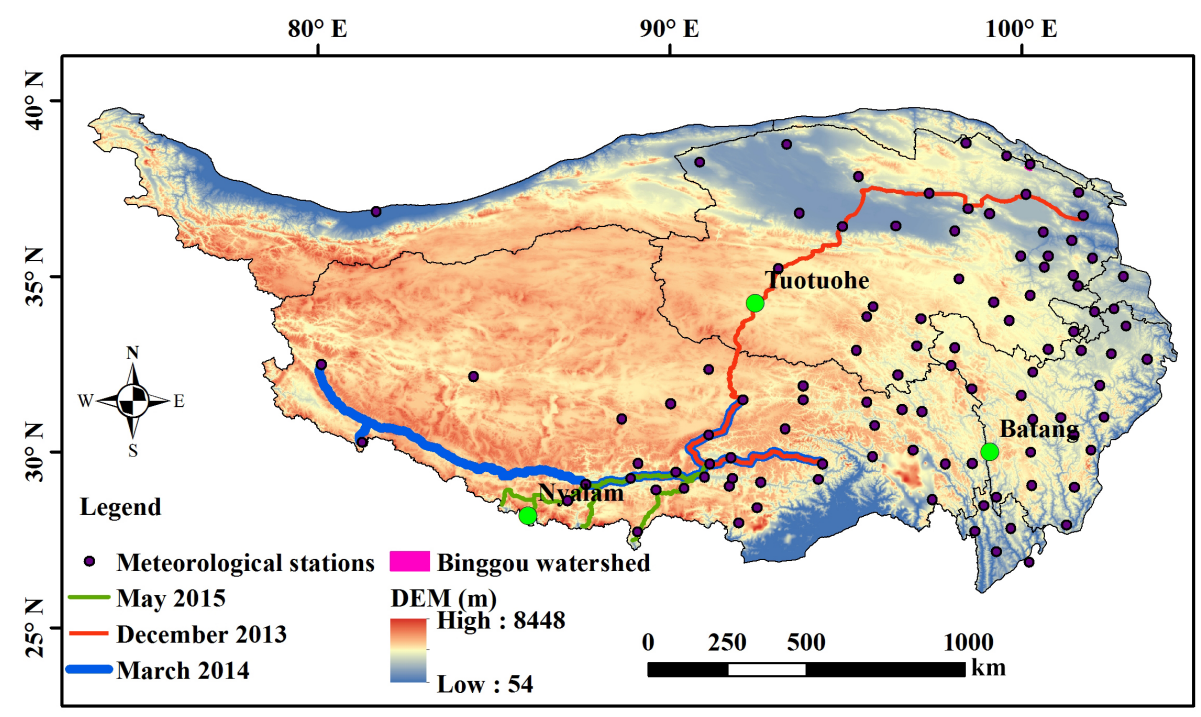

Figure 1. Distribution of meteorological stations, the location of Binggou watershed and three snow observation routes described in the text overlaid on a digital elevation model for elevation and topography of the QTP.

tween AMSR-E and AMSR2 in Du et al. (2014), the brightness temperature from these sensors are close to each other. Therefore, in this study, these criteria were also applied for AMSR-E and AMSR2.

\subsection{Meteorological station observations of snow depth}

Daily snow depths and snow water equivalents were observed at 109 meteorological stations across the QTP with a spatial distribution provided in Fig. 1. Snow depths from meteorological stations were observed daily at 08:00 using rulers, and the record is the mean value of three individual measurements. On the 5th, 10th, 15th, 20th, 25th and last day of a month (nearly every 5 days), snow water equivalents were measured using a snow tube with a cross-sectional area of $100 \mathrm{~cm}^{2}$ at the same time of snow depth measurement. The record is also the mean value of three individual measurements.

\subsection{Field experiments}

From 20 November to 7 December 2013, snow depths were observed along an observation route (Fig. 1, red line). During this period, little snow accumulated; only some patchy snow was distributed which cannot be measured by ruler. From 23 to 31 March, 2014, snow characteristics were observed along an additional observation route (Fig. 1, blue line). Snow depth was recorded every $5-10 \mathrm{~km}$ in the snow cover area, and snow depths in the transition region were also measured. During this field campaign, 56 snow depths were recorded. From 6 to 25 May, 2014, snow depths were observed along an additional observation route (Fig. 1, green line). During this period, there was no snow distribution except at the tops of mountains, which was not measurable.
The Binggou watershed in the Qilian Mountains, an area of $30 \mathrm{~km}^{2}$, is located in the northeast of the QTP (Fig. 1, pink polygon), where dense snow depths were measured during the watershed allied telemetry experimental research (WATER) field campaign carried out in March of 2008. During this experiment, 51 snow depths were measured using snow stakes on the 2, 4, 9, 16, 19, 21, 23 and 29 March and the 1 and 6 April. On 29 March 2008, airborne microwave radiometry experiment was carried out, providing brightness temperatures at the 18 and $36 \mathrm{GHz}$, and 78 snow pits including snow depth, snow density and grain size were observed at four sampling sites ( $\mathrm{Li}$ et al., 2009; Che et al., 2012). These data were all used to evaluate the identification of snow cover by passive microwave and the accuracy of the satellite-derived snow depth.

\section{Evaluation methods and results}

The MODIS snow cover fraction product, meteorological station observations and field campaign snow depth observations are compared with the AMSR-E/AMSR2 snow cover, and snow depths observed at meteorological stations and field experiments are compared with AMSR-E/AMSR2 snow depths.

\subsection{Comparison with MODIS SCF product}

Based on the snow cover identification algorithm described in Sect. 2.2, the AMSR-E brightness temperatures were used to calculate the TBD, which represents snow depth. MODIS SCFs with a resolution of $500 \mathrm{~m}$ were resampled to $0.1^{\circ}$, similar to the AMSR-E resolution across the QTP. For every AMSR-E grid, SCF was recalculated based on the no- 


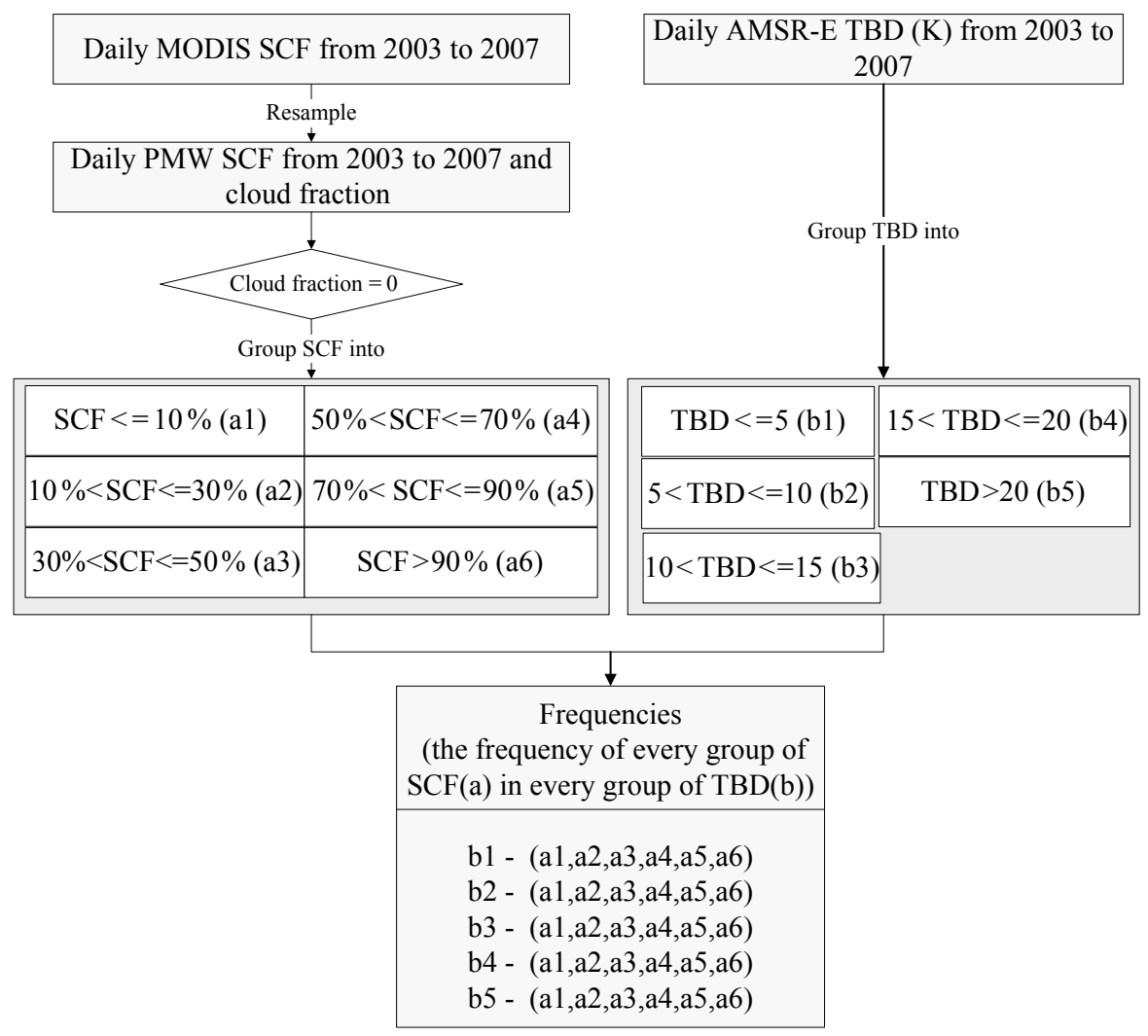

Figure 2. Flowchart for building the TBD-SCF table, which provides the relationship between snow cover fraction (SCF) and passive microwave brightness temperature difference (TBD). The SCF of the PMW grid was calculated based on the MOD10A and MYD10A products from 2003 to 2007, and TBD was computed using AMSR-E brightness temperature at 18 and $36 \mathrm{GHz}$ for horizontal polarization from 2003 to 2007.

cloud MODIS grids (new SCF), and the number of cloudcover grids in every AMSR-E grid was also recorded. The AMSR-E TBDs were grouped into five groups: $\leq 5,5-10$, $10-15,15-20$ and $>20 \mathrm{~K}$. The new SCFs were divided into six groups: $<10,10-30,30-50,50-70,70-90$ and $>90 \%$. The frequencies of each SCF with cloud fraction less than $10 \%$ for each TBD group from 2003 to 2007 were computed, which was called TBD-SCF table. Based on the TBD-SCF table, the probability was calculated, which was the ratio of frequency of a certain group of SCF and the frequency of all SCF with cloud fraction less than $10 \%$. The flowchart for building the TBD-SCF table is provided in Fig. 2.

The probabilities of all SCF groups to all TBD groups were depicted in Fig. 3. Left figures described the spatial distribution of probabilities of SCF $>10 \%$ when TBDs were more than $20 \mathrm{~K}$ (Fig. 3a), between 15 and $20 \mathrm{~K}$ (Fig. 3b), between 10 and $15 \mathrm{~K}$ (Fig. 3c), between 5 and $10 \mathrm{~K}$ (Fig. 3d) and less than $5 \mathrm{~K}$ (Fig. 3e). Right figures were the statistic results of different probabilities for all group of SCF all over the QTP. The first group, with horizontal axis labeled "> $10 \%$ ", was the statistical result of the right figures. The red bar is the number of pixels with probability of SCF $>10 \%$ between 0 and 0.1 all over the QTP, the yellow bar for between 0.1 and 0.5 , the light blue bar for between 0.5 and 0.8 and the dark blue bar for more than 0.8 . The other groups, labeled $>30 \%,>50 \%,>70 \%$ and $>90 \%$, had correspondingly similar SCF ranges, but their spatial distributions were not presented in figures.

If $\mathrm{SCF}>10 \%$ was considered as snow cover, grids with TBD more than $20 \mathrm{~K}$ showed $4.9 \%$ snow-free area, $82.9 \%$ snow area and $12.2 \%$ uncertainty area. The uncertainty areas included $6.1 \%$ high possibility of snow cover area and $6.1 \%$ high possibility of snow-free area. A decrease in TBD causes the certainty ratio to decline and the uncertainty to increase. TBD between 15 and $20 \mathrm{~K}$ showed $5.9 \%$ snow-free area, $68.2 \%$ snow-covered area and $25.9 \%$ uncertainty area. The TBD between 5 and $10 \mathrm{~K}$ presented the highest uncertainty. When the TBD is less than $5 \mathrm{~K}$, the QTP is dominated by no snow, and the snow-covered areas are mainly glaciers and lake ice, based on the land cover map. However, there is a large area of uncertainty with a low possibility of snow. Therefore, snow cover is difficult to identify when the TBD is between 5 and $15 \mathrm{~K}$. Although there was large overestimation over the QTP, if a threshold of TBD were to be used to identify snow cover over the QTP, then "TBD $>5 \mathrm{~K}$ " would be best. 
(a)
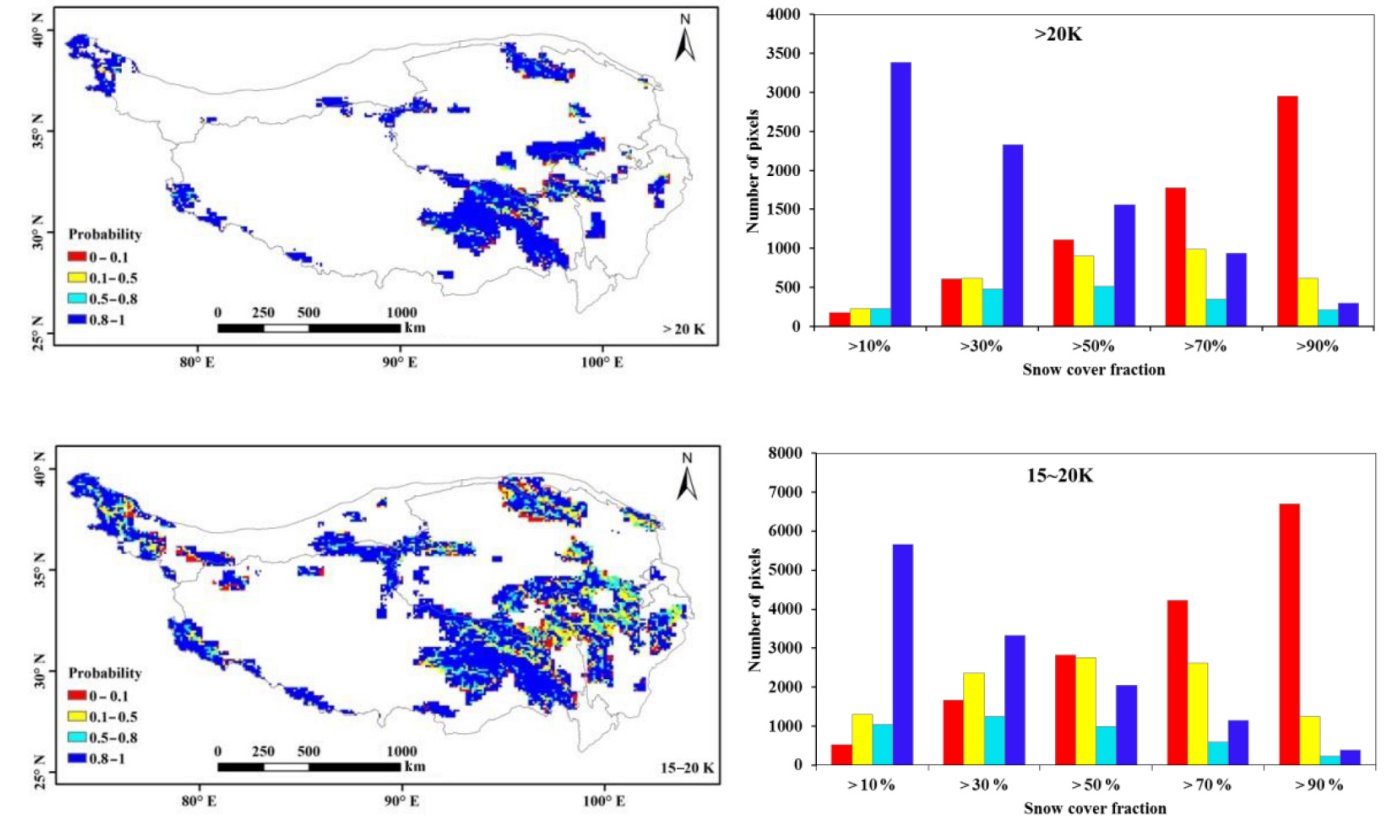

(b)
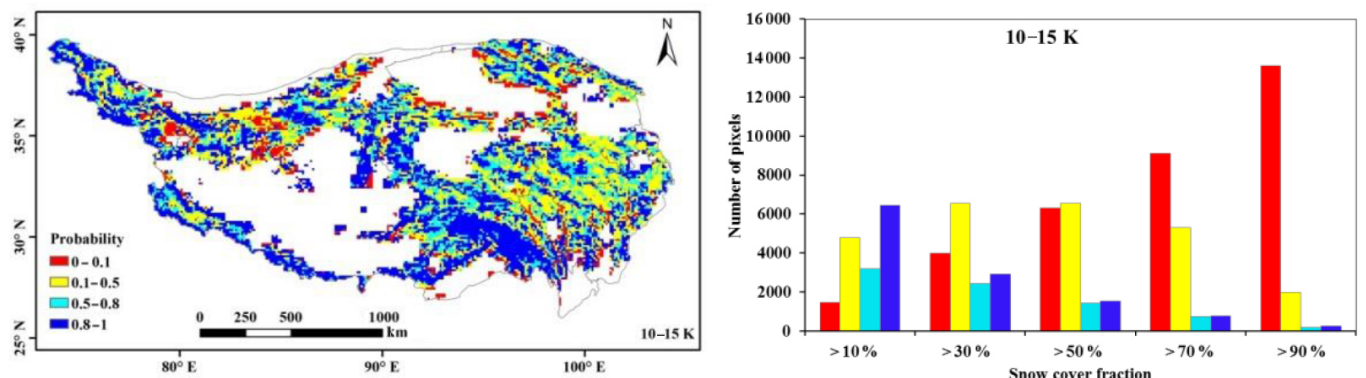

(c)
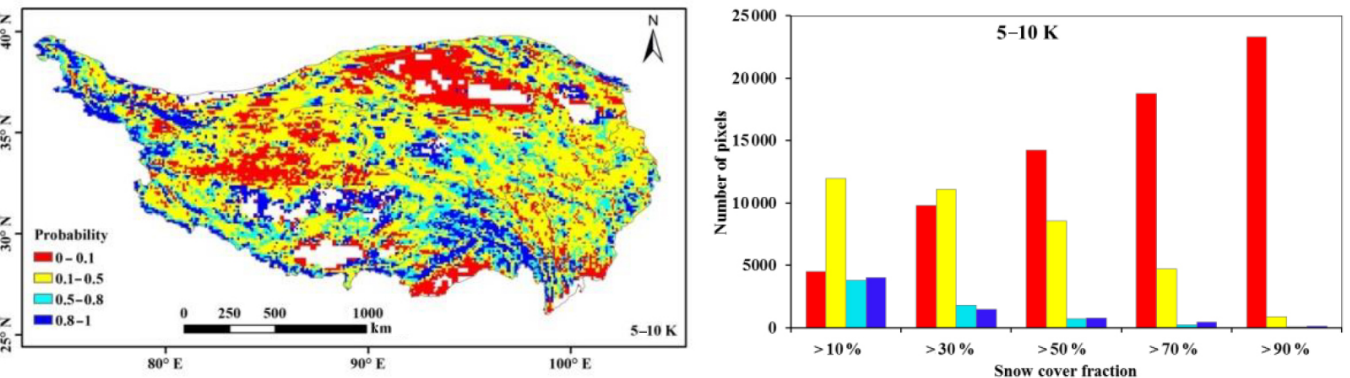

(d)
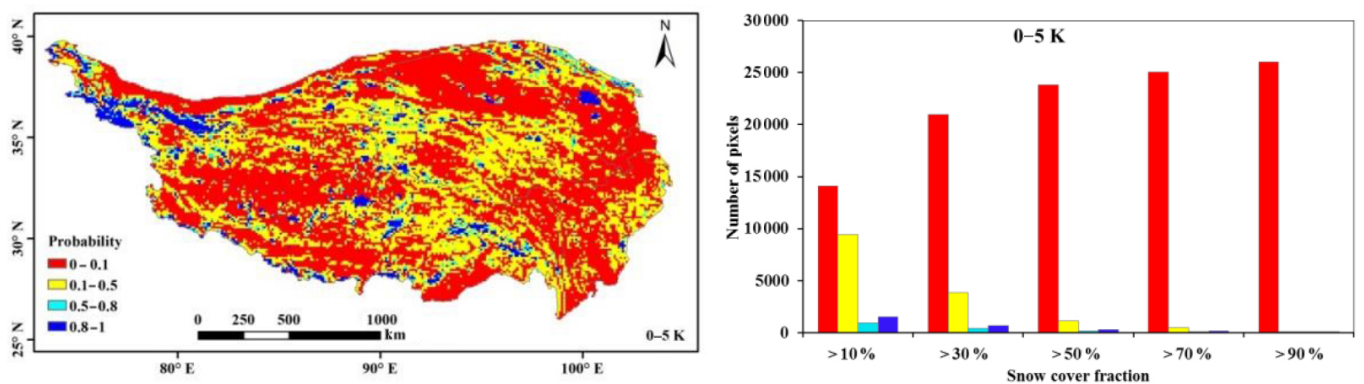

(e)

Figure 3. Spatial distribution of frequency of SCF greater than $10 \%$ across the QTP and histograms of frequency for each SCF group. (a) $\mathrm{TBD}>20 \mathrm{~K}$. (b) $15 \mathrm{~K}<\mathrm{TBD} \leq 20 \mathrm{~K}$. (c) $10 \mathrm{~K}<\mathrm{TBD} \leq 15 \mathrm{~K}$. (d) $5 \mathrm{~K}<\mathrm{TBD}<10 \mathrm{~K}$. (e) $\mathrm{TBD} \leq 5 \mathrm{~K}$. 
Table 1. Errors in derived snow cover from AMSR-E based on MODIS snow cover fraction and meteorological stations (a) and corresponding confusion matrix (b).

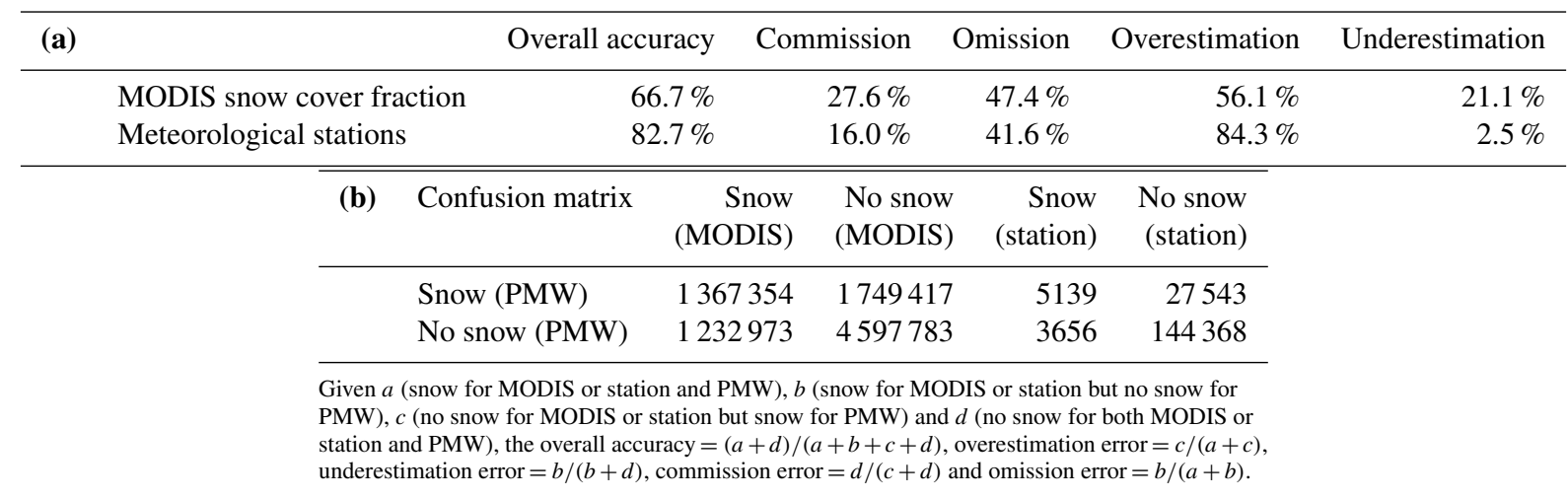

If $\mathrm{SCF}>30 \%$ is considered as snow cover, the uncertainty areas increase when TBD is more than $5 \mathrm{~K}$, but the snowfree areas increase when TBD is less than $5 \mathrm{~K}$. If $\mathrm{SCF}>50 \%$ is considered as snow cover, only $3.3 \%$ of the area is definitely identified as snow when TBD is between 5 and $10 \mathrm{~K}$, $9.8 \%$ when TBD is between 10 and $15 \mathrm{~K}$. With an increase in TBD, the snow cover areas increase and the uncertainty area increases. Therefore, although there is no obvious relationship between TBD and SCF, TBD can reflect snow cover fraction to a certain extent.

With $\mathrm{SCF}>0.1$ as snow cover and TBD $>5 \mathrm{~K}$ is the threshold to identify snow from AMSR-E, the overall accuracy, underestimation, overestimation, commission and omission errors of AMSR-E were analyzed (Fig. 4, Table 1). The overall accuracy is $66.7 \%$ and varies spatially. In this condition, $27.6 \%$ of snow-free areas are misclassified as snow cover (commission), and $47.4 \%$ of snow cover grids are not be detected by AMSR-E (omission); meanwhile, $56.1 \%$ of grids identified as snow covered by AMSR-E were free of snow (overestimation), and $21.1 \%$ of snow-free grids from AMSR-E were in fact covered by snow (underestimation), which is mainly distributed in the lake and glacier areas. The lowest accuracy occurs in the northwest area of the QTP, where the commission error reaches up to 0.6-0.8. Although the overall accuracy for the cold desert areas is more than 0.8 , in most of these areas the omission error is also up to 0.8 , which means that $80 \%$ of snowfall cannot be detected by AMSR-E. In these areas, snowfall is a rare event and snow depth is shallow, which changed TBD slightly. If pixels with $\mathrm{SCF}>0.3$ is assumed to be snow pixel, the overestimation, underestimation, commission and omission errors are 72.2, $0.9,17.5$ and $9.9 \%$, respectively. If SCF $>0.5$ is the threshold between snow and no snow, they are 83.2, 0.4, 19.5 and $7.2 \%$, respectively. The overestimation and commission errors increase with the increase of the threshold, and the underestimation and omission errors decrease. Therefore, the high overall accuracy of these areas is due to the large number of snow-free days. In the mountainous areas of south- east and northeast Qilian and the northwest area of the QTP, AMSR-E showed high overestimation and commission errors.

Generally, based on MODIS SCF, snow cover accuracy of AMSR-E across the QTP varies spatially and showed the overall accuracy of over $60 \%$ in most of areas. But it was also characterized by large areas of overestimation and omission errors.

\subsection{Comparison with observed snow depth}

Daily snow depths from meteorological stations from 2003 to 2007, snow depth from the three observation routes in 2013 and 2014 and snow depth observed at the Binggou watershed in 2008 were compared with the snow cover and snow depth derived from AMSR-E or AMSR2.

\subsubsection{Comparison with meteorological station observation}

Snow depths were derived from AMSR-E at grids that meteorological stations located on and then compared with station records. The comparison results showed that the overall accuracy of AMSR-E snow cover is $82.7 \%$, where $41.6 \%$ of snow-covered grids were not detected by AMSR-E, and $16.0 \%$ of snow-free grids were misclassified as snow covered by AMSR-E. The overestimation and underestimation are 84.3 and $2.5 \%$, respectively. A meteorological station may not represent the status of an entire PMW grid in the complex territorial region, therefore snow cover fractions in the PMW grid were derived based on MODIS snow cover production and compared with meteorological observations. The results showed that when MODIS SCF was greater than $10 \%$, only $22.4 \%$ of snow depth observations were greater than $0 \mathrm{~cm}$, a MODIS SCF greater than $30 \%$ corresponded to $39.8 \%$ of observations greater than $0 \mathrm{~cm}$, and a MODIS SCF greater than $50 \%$ corresponded to $54.9 \%$ of observations greater than $0 \mathrm{~cm}$. Therefore, although station snow observations are in good general agreement with the snow cover 


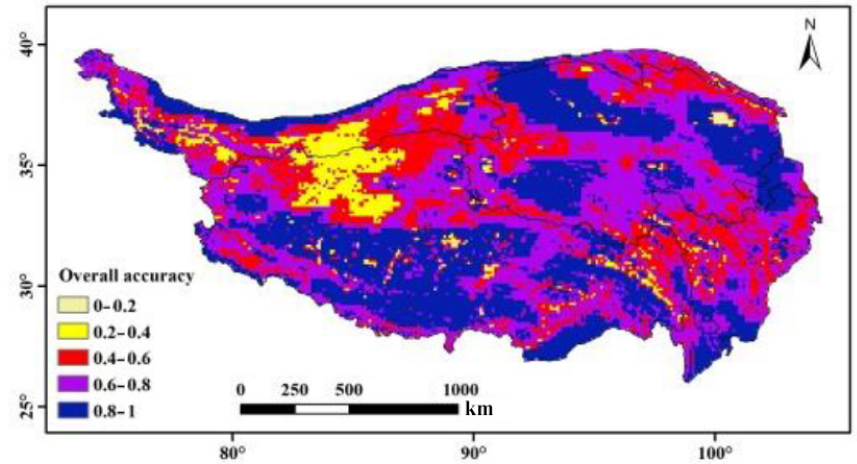

(a)

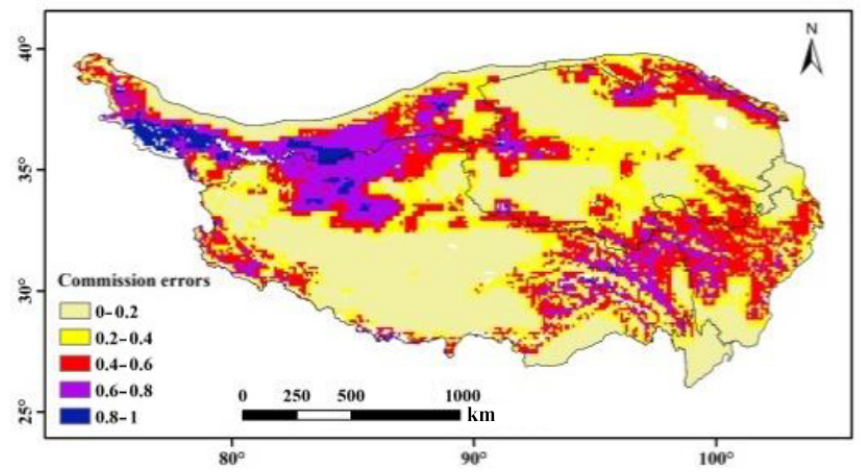

(c)

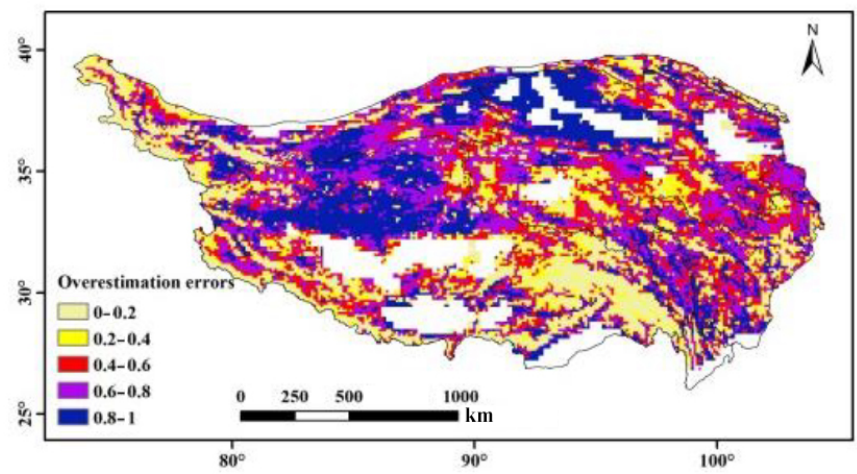

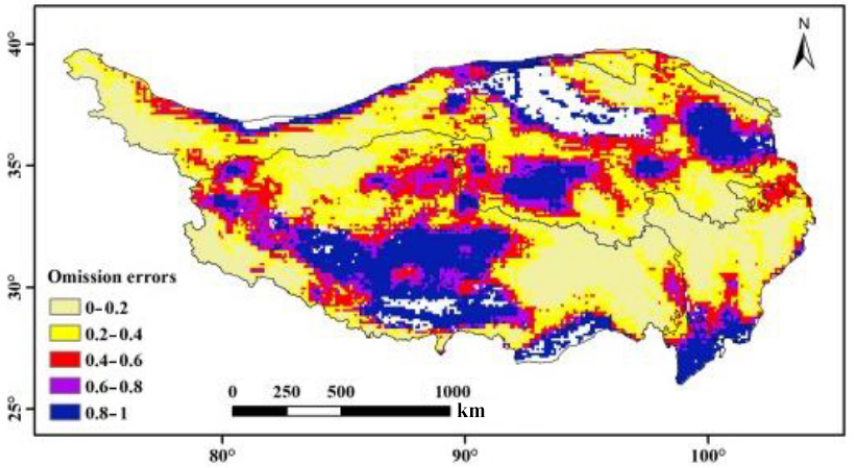

(b)

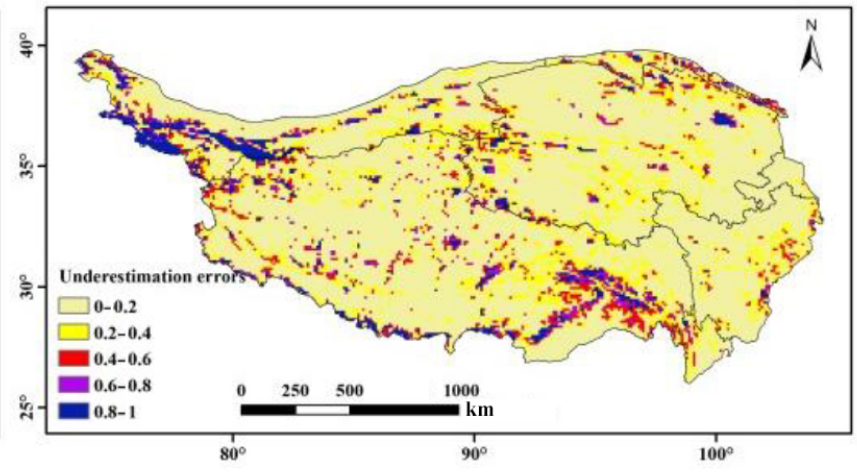

(d)

\section{(e)}

Figure 4. Spatial distributions of the general accuracy (a), omission errors (b), commission errors (c), underestimation errors (d) and overestimation errors (e) of AMSR-E across the QTP.

MODIS grid (Yang et al., 2015), they cannot represent the snow cover in a PMW grid across the QTP.

Due to the disagreement between the PMW grid and station-based snow cover measurements, snow depths from stations and AMSR-E greater than 0 were compared (Fig. 5). The results showed that the correlation coefficient between them was 0.124, and AMSR-E overestimates snow depths across the QTP, in agreement with results of Yang et al. (2015). The mean snow depth, bias and RMSE are 4.0, -0.45 and $6.7 \mathrm{~cm}$, respectively, and the relative error is $131.4 \%$. From Fig. 5, snow depths greater than $20 \mathrm{~cm}$ were always underestimated by AMSR-E, caused primarily by the data that came from the Nyalam station (ID: 55655; latitude: $28.18^{\circ} \mathrm{N}$; longitude: $85.97^{\circ} \mathrm{E}$ ) located in the Himalaya 


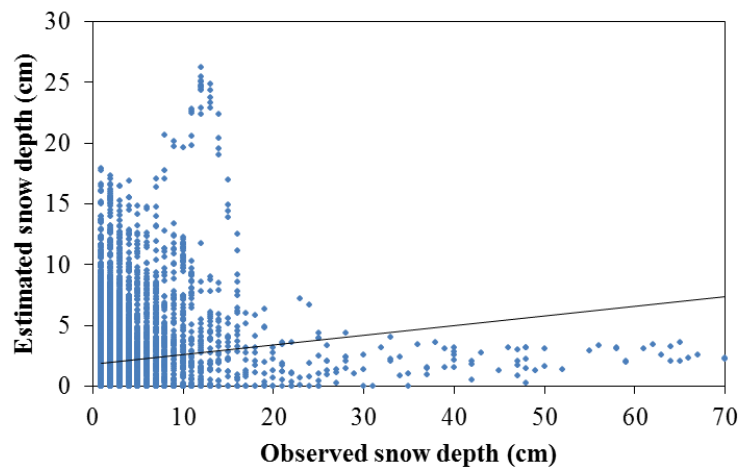

Figure 5. Scatter plot of snow depths observed at meteorological stations and those derived from the AMSR-E from 2003 to 2007.

Mountains. If the data at this station are removed from the statistics, the mean snow depth, the bias and RMSE are 3.5, 1.7 and $5.5 \mathrm{~cm}$, respectively, and the relative error is $152.3 \%$.

Therefore, snow depth derived from AMSR-E showed low consistency with that from stations over QTP. Because of the complex terrain, meteorological stations, mainly distributed in the valley with small snow and no continuing accumulation period and with no obvious tendency of increase or decrease, may not present the snow status of a PMW pixel. The Former Soviet Union Hydrological Surveys (FSUHS) presented the highest station density (approximately one transect per $100 \mathrm{~km}$ grid cell) and are primarily composed of non-complex terrain with maximum elevation differences of $<500 \mathrm{~m}$. When compared with these station observations, PMW presented high correlation with in situ data, although underestimated the snow depth in the Former Soviet Union (Armstrong and Brodzik, 2002). Therefore, due to the complex terrain and special distribution of snow cover, the representativeness of meteorological stations is limited.

\subsubsection{Comparison with field observations}

Observations from December 2013 and May 2014 indicated sparse snow along the observation route, a result also shown by AMSR2. During the observations in March 2014, 56 points of snow depth were measured within 33 AMSR2 grids (Fig. 1). Comparison between ground observations and retrievals from AMSR2 indicates that the retrieval accuracy of snow cover from AMSR 2 is $94 \%$. The average snow depth of observed measurements is $6.71 \mathrm{~cm}$, the bias between them is $0.27 \mathrm{~cm}$ and RMSE is $5.4 \mathrm{~cm}$, and the correlation coefficient is 0.574 (Fig. 6a). According to MODIS fractional snow cover products, snow cover fraction of the pixels that these points located in ranged from 0.5 to 0.9 when the observations showed snow. If the snow cover fraction is considered in the comparison, the bias is $1.77 \mathrm{~cm}$, RMSE is $5.66 \mathrm{~cm}$, showing general overestimation. Therefore, in these observation areas, snow cover was detected accurately by PMW,
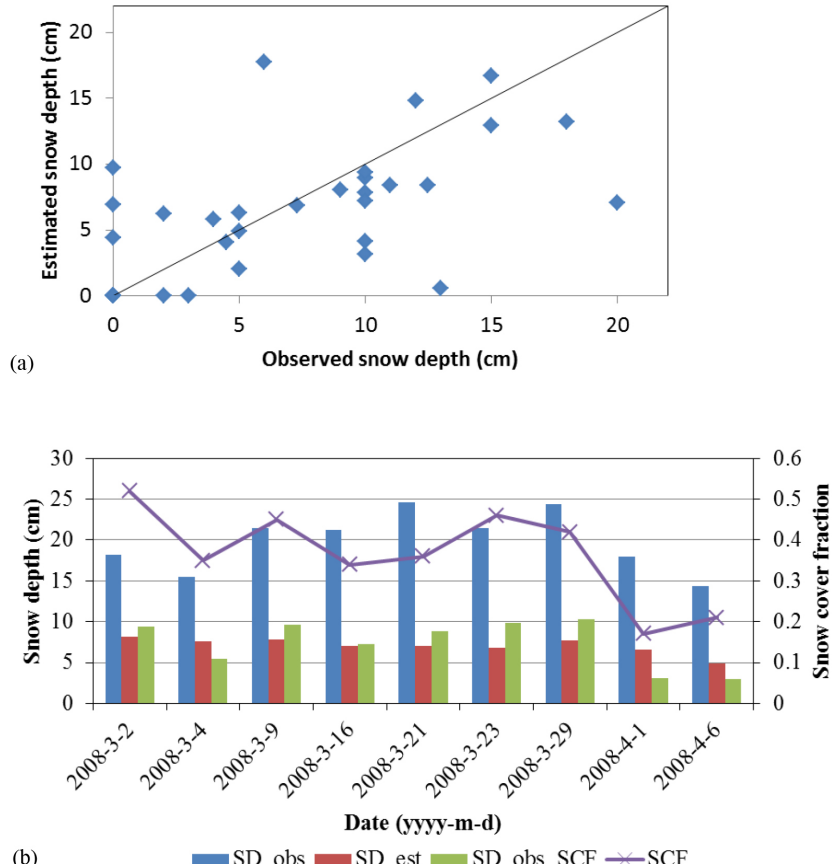

(b) $\quad$ SD_obs $\simeq$ SD_est $\amalg S D$ obs_SCF $\longleftarrow$ SCF

Figure 6. Comparison between measured snow depth and estimated snow depth from AMSR-E/AMSR2 for (a) March 2014 along the observation route and (b) March 2008 in the Binggou watershed: bar graph of observed snow depth, area-weighted observed snow depth and estimated snow depth from AMSR-E, and line graph of snow cover fractions on different days.

which was consistent with the comparison between MODIS and AMSR-E, but snow depth was overestimated.

In 2008, there were five groups of snow depth observations and a total 51 points, all within an AMSR-E grid in the Binggou watershed (Che et al., 2012). The average snow depths of the 51 points for the 2, 4, 9, 16, 19, 21, 23 and 29 March and 1 and 6 April were 18.2, 15.5, 21.5, 20.0, 24.6, 21.5, $24.2,18.0$ and $14.4 \mathrm{~cm}$. Snow depths varied between 0 and $60 \mathrm{~cm}$. Compared with these samples, the snow depths derived from AMSR-E generally present underestimation; the bias is $-10.0 \mathrm{~cm}$, and the RMSE is $10.5 \mathrm{~cm}$ (Fig. 6b). Therefore, based on the field investigation, snow cover can be detected accurately by AMSR-E because of thick snowpack, but the accuracy of snow depth retrieval is low.

Although the observations in the Binggou watershed were dense due to the large spatial variation in snow depth and topography, an average snow depth may not represent the snow depth of a whole grid. Che et al. (2008) analyzed the relationship between snow depth distribution, elevation and directional aspect using the snow depth estimated from airborne radiometer data with a footprint of $16-39 \mathrm{~m}$ at $36 \mathrm{GHz}$ and $158-395 \mathrm{~m}$ at $18 \mathrm{GHz}$. The authors found that snow cover was primarily distributed in a northerly aspect. The snow cover fractions across the QTP derived from the MODIS snow cover product are 52,35, 45, 34, 36, 46, 42, 17 and 
$21 \%$ for 2, 4, 9, 16, 21, 23, 29 March, 1 and 6 April, respectively, and the average snow depths in the AMSR-E footprint are calculated by multiplying the snow cover fraction by the observed mean snow depth. The average snow depths in the AMSR-E footprint are compared with the derived snow depth, exhibiting average snow depth, bias, RMSE and absolute relative error of $7.4,-0.4,2.2$ and $29.5 \%$, respectively (Fig. 6b).

Therefore, the spatial inhomogeneity of snow depth causes the difference between satellite and in situ observation. Evaluation of PMW snow depth over the QTP requires dense sampling in a whole pixel.

As a whole, accuracy of PMW snow cover in the QTP presented a spatial heterogeneity, and the difference of snow depth between estimation and in situ observations also varied with observation data.

\section{Sources of error}

Although both existing research and this study reported the overestimation phenomenon over the QTP, the causes were still unclear. Additionally, this study found a serious omission problem in the shallow snow areas and difference of snow depth between the estimation and in situ data. Therefore, we discuss potential reasons for the misclassification and bias in this section.

\subsection{Cold desert}

Based on the classification criterion of Grody and Basist (1996), cold desert presented large polarization. There are large areas of cold desert on the middle and northwest part of QTP, which also showed scattering features. The omissions mainly appeared in these areas, with the exception of the lake ice areas. In these areas, there is no heavy snow, and the snow depth is usually less than $5 \mathrm{~cm}$. The fallen snow melts quickly in a few days, resulting in a small TBD change. One example is the Tuotuohe station (ID: 56004; latitude: $34.22^{\circ} \mathrm{N}$; longitude: $92.43^{\circ} \mathrm{E}$; Fig. 1), which was located in this area (Fig. 1); during the winter, ground scatters the microwave signal and presents weak scattering features. The TBD contributed by ground is less than $5 \mathrm{~K}$, but even if the cold desert was covered by snow the TBD did not increase and remained less than $5 \mathrm{~K}$ (Fig. 7). Liquid water melted from snow cover will even decrease the TBD. The criterion for cold desert identification presented in the Sect. 2.2 removes not only the desert as a scatter but also the snowpack. If the criterion is not used, AMSR-E will seriously overestimate the snow cover. The Gobi desert areas in the middle and south of the QTP showed the same phenomenon, but the northwest of the QTP showed the opposite phenomenon; there is little snow, but PMW classifies it as a large area of snow.

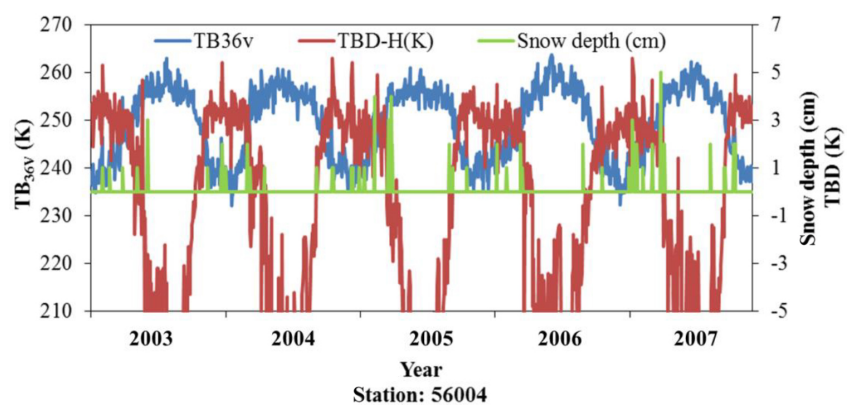

Figure 7. Temporal variation of brightness temperature at $36 \mathrm{GHz}$ for vertical polarization $\left(\mathrm{TB}_{36 \mathrm{~V}}\right)$, TBD and snow depth observed at Tuotuohe station (ID: 56004).

\subsection{Soil temperature}

$\mathrm{TB}_{36 \mathrm{~V}}$ is sensitive to topsoil temperature (Holmes et al., 2009; Zeng et al., 2015). Statistical analysis between TBD $(\mathrm{K})$ and $\mathrm{TB}_{36 \mathrm{~V}}$ at 109 stations showed that TBD has a significant negative correlation with $\mathrm{TB}_{36 \mathrm{~V}}$ (Fig. 8a) at the confidence level of 0.95 , but no obvious relationship with snow cover fractions. Batang station (ID: 56247; latitude: $30.00^{\circ} \mathrm{N}$; longitude: $99.10^{\circ} \mathrm{E}$; Fig. 1) is a typical station, where snowfall is rare, the PMW grid of this station was seldom covered by snow and the snow cover fraction in the AMSR-E grid was greater than $10 \%$ on only a few days based on MODIS snow cover fraction products. The temporal variation in $\mathrm{TB}_{36 \mathrm{~V}}$, TBD and snow depth at this station also indicates that a decrease of $\mathrm{TB}_{36 \mathrm{~V}}$ is accompanied by a TBD increase to over $5 \mathrm{~K}$ with a snow depth of $0 \mathrm{~cm}$ (Fig. 8b). TB $36 \mathrm{~V}$ and TBD have a highly negative correlation (Fig. 8c). Therefore, the ground temperature is also a main reason for the large TBD. Based on the MODIS land surface temperature, the land surface temperature in the northwest of the QTP showed lowest value, where the overestimation was most serious (Fig. 4).

The penetrability of 18 and $36 \mathrm{GHz}$ is different and depends on the soil features. In the summer, the brightness temperature at $18 \mathrm{GHz}$ and $36 \mathrm{GHz}$ is emitted from the ground surface, but with decrease of temperature and soil freezing the penetration depth of $18 \mathrm{GHz}$ is larger than the $36 \mathrm{GHz}$. The higher temperature at deeper depths contributes to the brightness temperature of the $18 \mathrm{GHz}$ and lower temperature close to the surface contributes to the brightness temperature of the $36 \mathrm{GHz}$. Besides, the $36 \mathrm{GHz}$ is sensitive to both ground surface temperature and snowpack, but ground surface temperature is also influenced by snowpack. Because of snowpack thermal insulation and thermal transfer of soil, ground surface temperature may stay high when covered by snow. As the brightness temperature of the $36 \mathrm{GHz}$ emitted from ground increases, it is also reduced by snowpack when arriving at sensor. Therefore, it is difficult to differentiate the main factor causing the decrease of brightness temperature at $36 \mathrm{GHz}$. 
Table 2. Errors in snow cover derived from AMSR-E data and atmosphere-corrected AMSR-E data over the QTP, based on MODIS snow cover fraction (a), and corresponding confusion matrix (b).

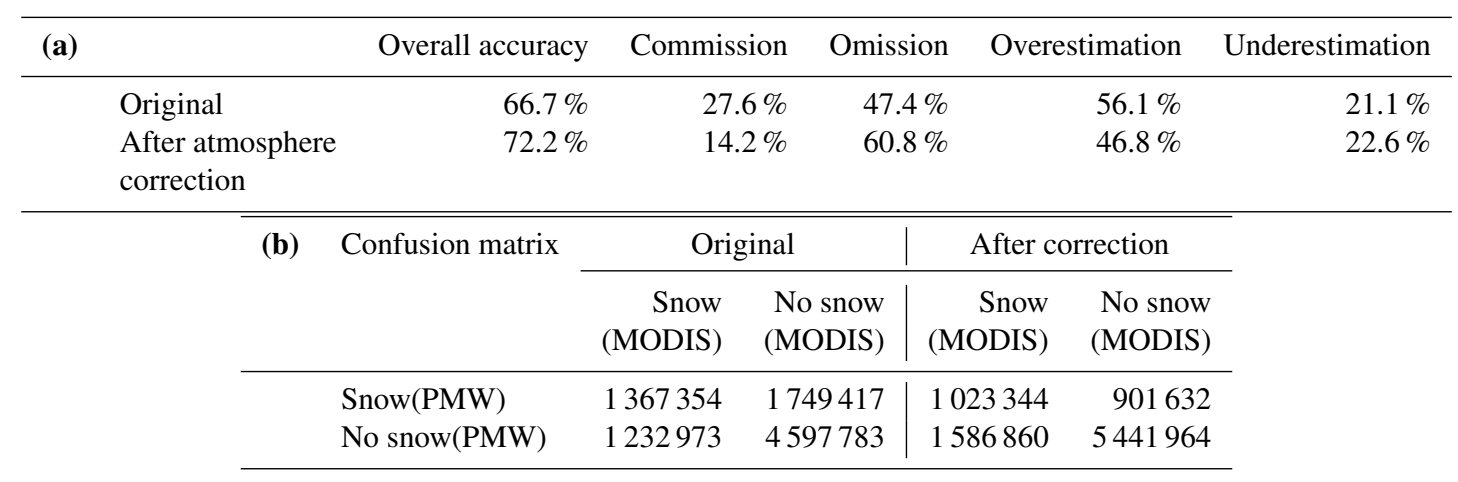

Therefore, we believe the ground feature is the main resource of errors. Accurately modeling the brightness temperature of different bands emitted from the ground is the key to improve the accuracy of snow cover detection (Jiang et al., 2007, 2011).

\subsection{Atmospheric correction}

Thinner atmosphere across the QTP was the hypothesized cause of overestimation of snow depth from PMW remote sensing (Savoie et al., 2009; Qiu et al., 2009). Prior researchers assumed that general algorithms built based on satellite brightness temperature and ground snow depth implicitly accounted for the presence of an atmosphere. In this study, we used the atmosphere correction method developed in Savoie et al. (2009) to adjust the brightness temperature of QTP to that of a lower elevation and then derive the snow cover from AMSR-E from 2003 to 2007. The derived snow cover was compared with snow cover fraction estimates from MODIS. The comparison results indicated that the overall accuracy improved from 66.7 to $72.2 \%$, the commission error decreased from 27.6 to $14.2 \%$ and overestimation error decreased from 56.1 to $46.8 \%$, but the omission error increased from 47.4 to $60.8 \%$, meaning that an additional $13.4 \%$ of snow cover was not detected (Table 2). If the TBD threshold used for identifying snow cover changed to 1 or $2 \mathrm{~K}$, then the overall accuracy, overestimation and omission would exhibit the same change in trend as with an atmospheric correction.

\subsection{Spatial resolution and topography}

The footprint of airborne radiometer data in the Binggou watershed experiment was $16-39 \mathrm{~m}$ at $36 \mathrm{GHz}$ and $158-395 \mathrm{~m}$ at $18 \mathrm{GHz}$. Considering the speed of the aircraft and interval time of radiometers, the brightness temperatures of both frequencies were gridded at $90 \mathrm{~m}$ resolution. The observed points were distributed in separate grids. Che et al. (2008) used an MEMLS model to simulate the brightness temperature of snow cover for each observation point and developed a snow depth retrieval algorithm in the Binggou watershed.
The mean absolute and relative errors of snow depth estimates were approximately $3.5 \mathrm{~cm}$ and $14.8 \%$ for the stake and sampling-site regions. The mean absolute and relative errors for AMSR-E are $2.0 \mathrm{~cm}$ and $29.5 \%$, respectively, in the AMSR-E grid. Although the derived snow depths from airborne and satellite radiometry agreed with each other, the average airborne brightness temperature and AMSR-E brightness temperature at $36 \mathrm{GHz}$ presented a large bias.

The satellite and airborne radiometers have similar radiation characteristics and were all well calibrated. The aircraft flew at an altitude of $5000 \mathrm{~m}$, where atmospheric influence on the airborne and satellite brightness temperatures should be the same. The difference between the airborne and satellite data is the spatial resolution, overpass time and incidence angle. In the Binggou watershed, snow cover presented strong heterogeneity. Fifty-one snow stakes covered 51 airborne grids located on seven MODIS grids, which only overlapped with a small part of the PMW grid (Fig. 9). Fiftyone snow depths varied between 0 and $60 \mathrm{~cm}$, which can be detected by airborne radiometry, but for MODIS they were all covered by snowpack. For the AMSR-E grid, they did not reflect snow distribution, although they were measured in different directional aspects and elevations.

Airborne experiments were carried out in daytime, which was closer to the ascending overpass of AMSR-E. The ascending TBD was less than $2 \mathrm{~K}$ and the descending TBD was approximately $11 \mathrm{~K}$, as presented in Fig. 9. In daytime, the snow cover melted in some areas, which led to spatially variant liquid water content and likely caused some of the differences between the airborne and satellite brightness temperature. In addition, the scan areas of the airborne radiometry were not identical to the satellite observations, which is an additional cause of the large gap between the airborne and satellite brightness temperatures for heterogeneous distribution of snow cover in the Binggou watershed. 

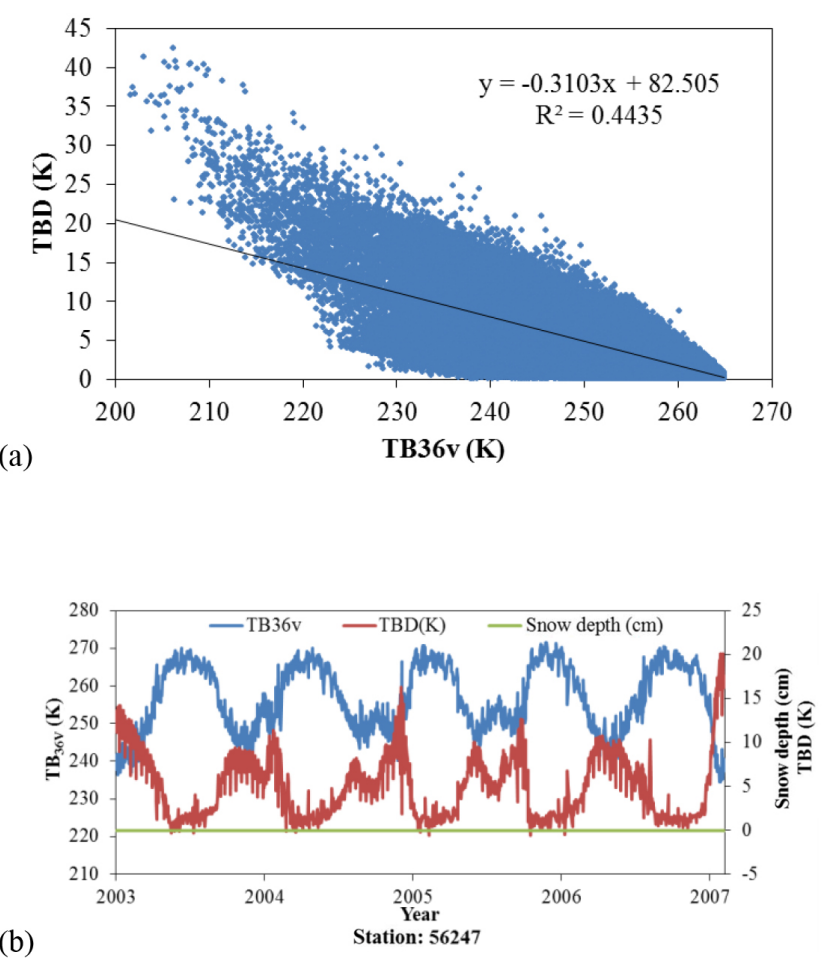

(b)

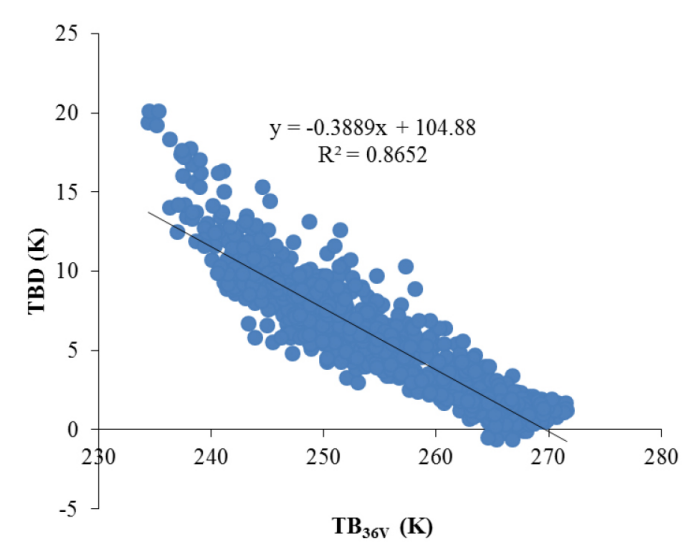

(c)

Figure 8. Relationship between $\mathrm{TBD}$ and $\mathrm{TB}_{36 \mathrm{~V}}$ at all stations (a) and Batang station (ID: 56247) (c); the temporal variation of $\mathrm{TB}_{36 \mathrm{~V}}$, TBD and snow depth observed at Batang station (b).

\subsection{Snow characteristics}

Based on spectral gradient algorithms, derived snow depths are closely related to TBD. However, TBD is not only influenced by snow depth but also other snow characteristics, in particular snow grain size. At the beginning of snowfall, snow grain size is small and the snowpack is transparent for microwave, so passive microwave remote sensing underestimates the snow depth in this period. With increasing snow age, grain size grows, which contributes to TBD, so snow

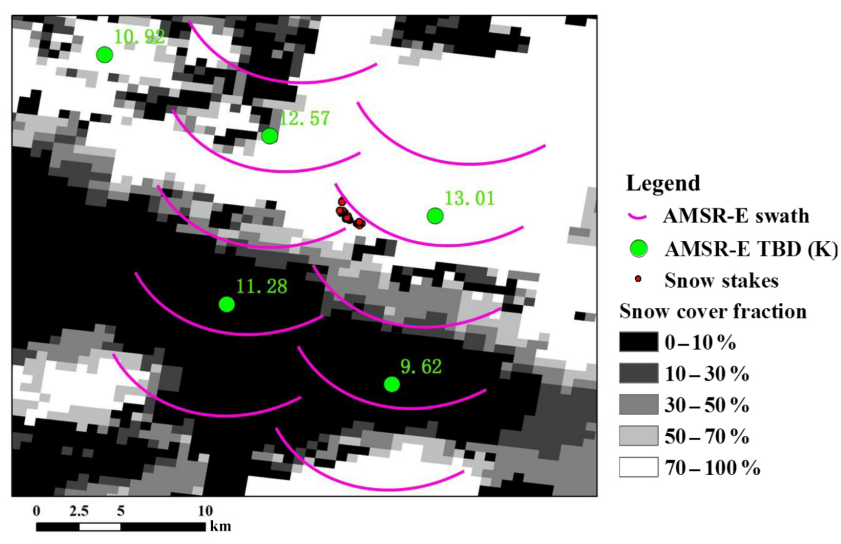

Figure 9. Distribution of snow cover fraction derived from MODIS products in the Binggou watershed, locations of snow stakes set during the Binggou watershed experiment, and the brightness temperature difference (TBD) between the 18 and $36 \mathrm{GHz}$ from AMSR-E.

depth may be overestimated by passive microwave remote sensing. Although the soil temperature and the land type were the main causes of errors in the QTP, the instant snow could not be detected for the extremely low scattering of small grain size. Therefore, accurately monitoring the snow depth using passive microwave requires a priori knowledge of snow characteristics (Dai et al., 2012; Che et al., 2016; Huang et al., 2012; Tedesco and Narvekar, 2010). In this study, $16 \%$ of snow depths greater than $10 \mathrm{~cm}$ observed at meteorological stations were misclassified as snow-free grids by AMSR-E. This misclassification occurred in the areas of sparse snow, where heavy snowfall occurred occasionally but melted in 1-3 days. During the field campaign in March 2014, snowpack measured on 23 March was fresh snow but was misclassified as no snow cover.

Therefore, both accurately modeling the ground brightness temperature at both frequencies and snow characteristics are two key factors for improving snow depth and snow cover accuracy of PMW. However, the strong heterogeneity of snow distribution over the QTP requires a retrieval algorithm with high resolution.

\section{Discussions}

Although satellite-based passive microwave brightness temperature data have been used to monitor global and regional snow depth since the 1980s, there were still some uncertainties on the snow depth retrieval algorithm in the QTP. Based on existing research on the evaluation of PMW products, forest and grain size were the main causes resulting in the low accuracy of PMW algorithm. In the forest regions, snow depth was usually underestimated by PMW, and many methods had been developed to overcome it (Foster et al., 1997; Goita et al., 2003; Vander Jagt et al., 2015; Pullianen et al., 1999; Che et al., 2016; Langlois et al., 2011). In the 
QTP, forest is mainly distributed in the southeast region with rare snow; therefore, it is not the dominant factor in the QTP. However, in Fig. 4b, the northeast region with omission errors was the main forest area. In this area, snowfall was a rare event, and volume scattering signal was weak; with the addition of the forest cover, it was difficult for PMW to detect snow.

Large grain size of snow can scatter much more irradiance than small one; therefore, fresh snow cover with small grain size tends to be underestimated, while snow cover with large grain size (e.g., depth hoar) tends to be overestimated due to its strong scattering. In order to solve this problem, the grain size growth model was developed by Kelly et al. (2003), and the a priori snow characteristics was used in the snow depth retrieval in northwest and northeast China (Dai et al., 2012; Che et al., 2016). The GlobSnow snow product used the assimilation method to optimize grain size, voiding the measurement of grain size (Pullianen, 2006). For the QTP, most areas were characterized by shallow snow or instant snow. Fresh snow melted in a few days, resulting in weak scattering which is difficult to detect by PMW; therefore, snow cover was underestimated in these areas. However, due to the complex topography, snow accumulated in cold and shady areas can survive for a long time and its grain size increased with the metamorphism and form the depth hoar, resulting in strong scattering and then causing the overestimation. Therefore, because of the lack of efficient grain size data in the QTP, the accuracy of estimated snow depth was certainly influenced.

However, in this study, we found that, other than the problem of forest and grain size, there were other problems in the QTP: the large areas of cold desert and frozen soil as well as the patchy snow cover. In Sect. 4, we analyzed the overestimation in the cold desert and frozen soil areas. There are some studies presenting the scattering features of cold desert and frozen soil, which were all weak scatters, and the TBD at vertical polarization caused by desert and frozen soil were less than 10 and $2 \mathrm{~K}$, respectively (Grody and Basist, 1996). The criterion has been used to remove the other scatters in the global algorithm, and it works in most regions. However, in the QTP there are still large areas presenting overestimation after using this criterion (Fig. 4).

Some research reported that the overestimation came from the atmosphere (Savoie et al., 2009), but the atmosphere correction decreased the commission errors and improved the general accuracy but sacrificed the omission errors based on the analysis in this study. This study also showed that the TBD was mainly controlled by soil temperature. It has a strong negative correlation with brightness temperature at $36 \mathrm{GHz}$ for vertical polarization, which is the most sensitive to ground surface temperature. Brightness temperature at $36 \mathrm{GHz}$ is much more sensitive to the land surface temperature than at $18 \mathrm{GHz}$. When the surface temperature declines, the brightness temperature at $36 \mathrm{GHz}$ decreases quickly. But the brightness temperature at $18 \mathrm{GHz}$ remains stable because it is influenced by temperature at deeper layer of soil. Therefore, brightness temperature at $36 \mathrm{GHz}$ is lower than that at $18 \mathrm{GHz}$, and the difference between them increases with the decrease of temperature of surface soil. Moreover, because of the freeze-thaw cycle of surface soil, the frozen soil becomes incompact and dry. The fine-scale soil and sand particles are scatters that also weaken the brightness temperature at $36 \mathrm{GHz}$ (England, 1976). In the northwest of the QTP, the surface temperature is very low and the polarization difference is larger than $30 \mathrm{~K}$, which is the characteristics of desert. Therefore, we inferred that the combined action of frozen soil and desert resulted in large TBD and then caused the serious overestimation.

Furthermore, patchy distribution of snow cover in the QTP was another cause of uncertainty of PMW with coarse resolution. For the high-latitude regions, where snow is a largearea phenomenon, PMW works well to detect snow cover. But for the QTP, which is characterized by low latitude and high altitude, snow cover distributes in inhomogeneity not only in the mountainous areas but also in the plain areas. In a PMW pixel, both snow particles and low-temperature bare soil produce TBD, which certainly results in overestimation. The patchy distribution creates a problem not only for the derivation of snow depth from PMW but also for the evaluation of the snow depth in a PMW pixel. In this study, we used the MODIS snow cover to evaluate the accuracy of snow cover and used station point data, sampling in lines and intense sampling data to assess the accuracy of snow depth. We found that it is not reasonable to use station observations to evaluate the accuracy of PMW snow depth because of the weak representation of many stations, and neither the general accuracy nor the simple overestimation can depict the accuracy of PMW snow depth in the QTP. Therefore, it is necessary to develop a retrieval algorithm to improve the spatial resolution of snow depth.

\section{Conclusions}

This study presented the accuracy of a snow depth product derived from PMW by comparing MODIS snow cover fraction and in situ data, and it analyzed the potential causes resulting from the uncertainties of the product.

The results showed that the overall accuracy of snow cover derived from PMW remote sensing across the QTP varies spatially based on MODIS snow cover fraction. Commission errors were mainly distributed in the northwest and southeast where ground temperature was low, and omission errors were found in the cold desert areas with sparse snowfall. The overestimation and commission errors decreased with the MODIS SCF, and underestimation and omission errors increased. The AMSR-E/AMSR2 snow depth was compared with the observations at meteorological stations and field investigation presented that snow depth in the field investigation showed higher consistency with estimated ones than me- 
teorological station observations. Most stations are located on the low land and cannot represent the snow depth in a PMW pixel. When compared with MODIS snow cover, snow cover at stations was always less than the MODIS observations. Therefore, not all station observations can be used to evaluate the accuracy of PMW snow depth.

Low ground temperature is the main reason for the overestimation of snow cover by PMW. Instant snow cover with small grain size led to the omission errors in the shallow snow areas. The mountainous topography and the coarse resolution of PMW resulted in the large disagreement between the snow depth derived from AMSR-E and in situ observations or airborne radiometry. Therefore, accurately monitoring the spatiotemporal distribution of snow depth across the QTP requires improving the retrieval accuracy of PMW as well as the spatial resolution. A new snow depth retrieval algorithm is suggested to combine optical remote sensing of snow cover, land surface temperature product and PMW.

Data availability. MODIS Snow Cover Daily L3 Global $500 \mathrm{~m}$ Grid version 5 was provided by NSIDC, and it was downloaded from http://reverb.echo.nasa.gov/reverb/ (Hall et al., 2006). AMSR2 L3 brightness temperatures from 2 July 2012 were provided by the Japan Aerospace Exploration Agency (JAXA). They were downloaded at http://gcom-w1.jaxa.jp/searchsat.html and are updated daily (Imaoka et al., 2010). AMSR-E daily gridded brightness temperatures from 19 June 2002 to 27 September 2011 were provided by the National Snow and Ice Data Centre (NSIDC) (Ashcroft and Wentz, 2000; Brodzik and Knowles, 2002; K. W. Knowles, unpublished data, 1993), and they were downloaded from ftp://sidads.colorado.edu/pub/DATASETS/nsidc0301_ amsre_ease_grid_tbs/. Snow depth data in the "dataset of daily surface observation in China" were provided by the China Meteorological Data Service Center (http://data.cma.cn/en). They are measured by different meteorological stations who reported the data to the China Meteorological Data Service Center daily.

Competing interests. The authors declare that they have no conflict of interest.

Acknowledgements. This study was supported by the National Natural Science Foundation of China (91547210, 41401414 and 41271356), the China State Key Basic Research Project (2013CBA01802) and the Chinese Academy of Sciences Project (KJZD-EW-G03).

Edited by: Tingjun Zhang

Reviewed by: two anonymous referees

\section{References}

Armstrong, R. L. and Brodzik, M. J.: Hemispheric-scale comparison and evaluation of passive-microwave snow algorithms, Ann. Glaciol., 34, 38-44, 2002.

Ashcroft, P. and Wentz, F.: Algorithm Theoretical Basis Document for the AMSR Level-2A Algorithm, Remote Sensing Systems, Santa Rosa, California, USA, 2000.

Barnett, T. P., Adam, J. C., and Lettenmaier, D. P.: Potential impacts of a warming climate on water availability in snow-dominated regions, Nature, 438, 303-309, 2005.

Brodzik, M. J. and Knowles, K. W.: EASE-Grid: A Versatile Set of Equal-Area Projections and Grids, in: Discrete Global Grids, edited by: Goodchild, M., National Center for Geographic Information \& Analysis, Santa Barbara, California, USA, 2002.

Brown, R. D. and Robinson, D. A.: Northern Hemisphere spring snow cover variability and change over 1922-2010 including an assessment of uncertainty, The Cryosphere, 5, 219-229, https://doi.org/10.5194/tc-5-219-2011, 2011.

Bulygina, O. N., Razuvaev, V. N., and Korshunova, N. N.: Changes in snow cover over Northern Eurasia in the last few decades, Environ. Res. Lett., 4, 045026, https://doi.org/10.1088/17489326/4/4/045026, 2009.

Chang, A., Foster J., and Hall D.: Nimbus-7 SMMR derived global snow cover parameters, Ann. Glaciol., 9, 39-44, 1987.

Che, T., Li, X., Jin, R., Armstrong, R., and Zhang, T. J.: Snow depth derived from passive microwave remote-sensing data in China, Ann. Glaciol., 49, 145-154, 2008.

Che, T., Dai, L. Y., Wang, J., Zhao, K., and Liu, Q.: Estimation of snow depth and snow water equivalent distribution using airborne microwave radiometry in the Binggou Watershed, the upper reaches of the Heihe River basin, Int. J. Appl. Earth Obs., 17, 23-32, 2012.

Che, T., Dai, L. Y., Zheng, X. M., Li, X. F., and Zhao, K.: Estimation of snow depth from passive microwave brightness temperature data in forest regions of northeast China, Remote Sens. Environ., 183, 334-349, 2016.

Choi, G., Robinson, D. A., and Kang, S.: Changing Northern Hemisphere snow seasons, J. Climate, 23, 5305-5310, 2010.

Cohen, J.: Snow cover and climate, Weather, 49, 150-156, 1994.

Dai, L. and Che, T.: Cross-platform calibration of SMMR, SSM/I and AMSR-E passive microwave brightness temperature. Sixth International Symposium on Digital Earth: Data Processing and Applications, edited by: Guo, H. and Wang, C., Proceedings of the SPIE, 7841, 784103, https://doi.org/10.1117/12.873150, 2009.

Dai, L. Y., Che, T., Wang, J., and Zhang, P.: Snow depth and snow water equivalent estimation from AMSR-E data based on a priori snow characteristics in Xinjiang, China, Remote Sens. Environ., 127, 14-29, 2012.

Deng, J., Huang, X., and Feng, Q.: Toward Improved Daily CloudFree Fractional Snow Cover Mapping with Multi-Source Remote Sensing Data in China, Remote Sens., 7, 6986-7006, 2015.

Du, J., Kimball, J. S., Shi, J., Jones, L. A., Wu, S., Sun, R., and Yang, H.: Inter-Calibration of Satellite Passive Microwave Land Observations from AMSR-E and AMSR2 Using Overlapping FY3B-MWRI Sensor Measurements, Remote Sens., 6, 8594$8616,2014$. 
England, A. W.: Relative influence upon microwave emissivity of fine-scale stratigraphy, internal scattering, and dielectric properties, Pure Appl. Geophys., 114, 287-299, 1976.

Foster, J. L., Chang A. T. C., and Hall D. K.: Comparison of snow mass estimates from prototype passive microwave snow algorithm, a revised algorithm and a snow depth climatology, Remote Sens. Environ., 62, 132-142, 1997.

Frei, A., Tedesco, M., Lee, S., Foster, J., Hall, D. K., Kelly, R., and Robinson, D. A.: A review of global satellite-derived snow products, Adv. Space Res., 50, 1007-1029, 2012.

Gafurov, A. and Bárdossy, A.: Cloud removal methodology from MODIS snow cover product, Hydrol. Earth Syst. Sci., 13, 13611373, https://doi.org/10.5194/hess-13-1361-2009, 2009.

Gafurov, A., Vorogushyn, S., Farinotti, D., Duethmann, D., Merkushkin, A., and Merz, B.: Snow-cover reconstruction methodology for mountainous regions based on historic in situ observations and recent remote sensing data, The Cryosphere, 9, 451-463, https://doi.org/10.5194/tc-9-451-2015, 2015.

Gao, J., Williams, M. W., Fu, X. D., Wang, G. Q., and Gong, T.,L.: Spatiotemporal distribution of snow in eastern Tibet and the response to climate change, Remote Sens. Environ., 121, 19, 2012.

Goita, K., Walker A. E., and Goodison B. E.: Algorithm development for the estimation of snow water equivalent in the boreal forest using passive microwave data, Int. J. Remote Sens., 24, 1097-1102, 2003.

Grody, N. C. and Basist, A. N.: Global identification of snow cover using SSM/I measurements, IEEE T. Geosci. Remote, 34, $237-$ 249, 1996

Hall, D. K. and Riggs, G. A.: Accuracy assessment of the MODIS snow products, Hydrol. Process., 21, 1534-1547, 2007.

Hall, D. K., Riggs, G. A., Salomonson, V. V., DiGirolamo, N. E., and Bayr, K. J.: MODIS snow-cover products, Remote Sens. Environ., 83, 181-194, 2002.

Hall, D. K., Salomonson, V. V., and Riggs, G. A.: MODIS/Aqua Snow Cover Daily L3 Global $500 \mathrm{~m}$ Grid, Version 5, Boulder, Colorado USA, NASA National Snow and Ice Data Center Distributed Active Archive Center, https://doi.org/10.5067/ZFAEMQGSR4XD, 2006.

Hall, D. K., Riggs, G. A., Foster, J. L., and Kumar, S. V.: Development and evaluation of a cloud-gap-filled MODIS daily snowcover product, Remote Sens. Environ., 114, 496-503, 2010.

Holmes, T. R. H., De Jeu, R. A. M., Owe, M., and Dolman, A. J.: Land surface temperature from $\mathrm{Ka}$ band $(37 \mathrm{GHz})$ passive microwave observations, J. Geophys. Res.-Atmos., 114, D04113, https://doi.org/10.1029/2008JD010257, 2009.

Huang, C. L., Margulis, S. A., Durand, M. T., and Musselman, K. N.: Assessment of Snow Grain-Size Model and Stratigraphy Representation Impacts on Snow Radiance Assimilation: Forward Modeling Evaluation, IEEE T. Geosci. Remote, 50, 45514564, 2012.

Imaoka, K., Kachi, M., and Murakami, H.: Global Change Observation Mission (GCOM) for monitoring carbon, water cycles, and climate change, Proc. IEEE, 98, 717-734, 2010.

Immerzeel, W. W., Droogers, P., de Jong, S. M., and Bierkens, M. F. P.: Large-scale monitoring of snow cover and runoff simulation in Himalayan river basins using remote sensing, Remote Sens. Environ., 113, 40-49, 2009.
Immerzeel, W. W., van Beek, L. P. H., and Bierkens, M. F. P.: Climate Change Will Affect the Asian Water Towers, Science, 328, 1382-1385, 2010.

Jiang, L., Shi, J. C., Tjuatja, S., Dozier, J., Chen, K., and Zhang, L.: A parameterized multiple-scattering model for microwave emission from dry snow, Remote Sens. Environ., 111, 357-366, 2007.

Jiang, L. M., Shi, J. C., Tjuatja, S., Chen, K. S., Du, J. Y., and Zhang, L. X.: Estimation of Snow Water Equivalence Using the Polarimetric Scanning Radiometer From the Cold Land Processes Experiments (CLPX03), IEEE Geosci. Remote S., 8, 359-363, 2011.

Jiang, L. M., Wang, P., Zhang, L. X., Yang, H., and Yang, J. T.: Improvement of snow depth retrieval for FY3B-MWRI in China, Sci. China Earth Sci., 57, 1278-1292, 2014.

Kang, S., Xu, Y., and You, Q.: Review of climate and cryospheric change in the Tibetan Plateau, Environ. Res. Lett., 5, 015101, https://doi.org/10.1088/1748-9326/5/1/015101, 2010.

Kelly, R. E., Chang, A. T., Tsang, L., and Foster, J. L.: A prototype AMSR-E global snow area and snow depth algorithm, IEEE T. Geosci. Remote, 41, 230-242, 2003.

Langlois, A., Royer, A., Dupont, F., Roy, A., Goita, K., and Picard, G.: Improved Corrections of Forest Effects on Passive Microwave Satellite Remote Sensing of Snow Over Boreal and Subarctic Regions, IEEE T. Geosci. Remote, 49, 3824-3837, 2011.

Li, X., Li, X. W., and Li, Z. Y.: Watershed Allied Telemetry Experimental Research, J. Geophys. Res.-Atmos., 114, D22103, https://doi.org/10.1029/2008JD011590, 2009.

Liang, T. G., Huang, X. D., and Cai, X. W.: An application of MODIS data to snow cover monitoring in a pastoral area: A case study in Northern Xinjiang, China, Remote Sens. Environ., 112, $1514-1526,2008$.

Lü, J. M., Ju, J. H., Kim, S. J., Ren, J. Z., and Zhu, Y. X.: Arctic Oscillation and the autumn/winter snow depth over the Tibetan Plateau, J. Geophys. Res.-Atmos., 113, D14117, https://doi.org/10.1029/2007JD009567, 2008.

Parajka, J., Pepe, M., Rampini, A., Rossi, S., and Bloschl, G.: A regional snow-line method for estimating snow cover from MODIS during cloud cover, J. Hydrol., 381, 203-212, 2010.

Pulliainen, J.: Mapping of snow water equivalent and snow depth in boreal and sub-arctic zones by assimilating space-borne microwave radiometer data and ground-based observations, Remote Sens. Environ., 101, 257-269, 2006.

Pulliainen, J. T., Grandell, J., and Hallikainen, M. T.: HUT snow emission model and its applicability to snow water equivalent retrieval, IEEE T. Geosci. Remote, 37, 1378-1390, 1999.

Qiu, Y. B., Shi, J. C., and Lemmetyinen, J.: The Atmosphere Influence to Amsr-E Measurements over Snow-Covered Areas: Simulation and Experiments, Int. Geosci. Remote Se., 1-5, 861-864, 2009.

Ramsay, B. H.: The interactive multisensor snow and ice mapping system, Hydrol. Process., 12, 1537-1546, 1998.

Riggs, G., Hall, D. K., and Salomonson, V. V.: MODIS Snow Products Users Guide to Collection 5, available at: http:// modis-snow-ice.gsfc.nasa.gov (last access: 19 August 2017), 2006.

Salomonson, V. V. and Appel, I.: Estimating fractional snow cover from MODIS using the normalized difference snow index, Remote Sens. Environ., 89, 351-360, 2004. 
Salomonson, V. V. and Appel, I.: Development of the Aqua MODIS NDSI fractional snow cover algorithm and validation results, IEEE T. Geosci. Remote, 44, 1747-1756, 2006.

Savoie, M. H., Armstrong, R. L., Brodzik, M. J., and Wang, J. R.: Atmospheric corrections for improved satellite passive microwave snow cover retrievals over the Tibet Plateau, Remote Sens. Environ., 113, 2661-2669, 2009.

Shi, H. X. and Wang, C. H.: Projected 21st century changes in snow water equivalent over Northern Hemisphere landmasses from the CMIP5 model ensemble, The Cryosphere, 9, 19431953, https://doi.org/10.5194/tc-9-1943-2015, 2015.

Smith, T. and Bookhagen, B: Assessing uncertainty and sensor biases in passive microwave data across High Mountain Asia, Remote Sens. Environ., 181, 174-185, 2016.

Tang, Z. G., Wang, J., Li, H. Y., and Yan, L. L.: Spatiotemporal changes of snow cover over the Tibetan plateau based on cloudremoved moderate resolution imaging spectroradiometer fractional snow cover product from 2001 to 2011, J. Appl. Remote Sens., 7, 073582, https://doi.org/10.1117/1.JRS.7.073582, 2013.

Tedesco, M. and Narvekar, P. S.: Assessment of the NASA AMSRE SWE Product, IEEE J.-Stars, 3, 141-159, 2010.

Vander Jagt, B. J., Durand, M. T., Margulis, S. A., Kim, E. J., and Molotch, N. P.: On the characterization of vegetation transmissivity using LAI for application in passive microwave remote sensing of snowpack, Remote Sens. Environ., 156, 310-321, 2015.

Wang, C., Wang, Z., and Cui, Y.: Snow Cover of China during the Last 40 Years: Spatial Distribution and Interannual Variation, Journal of Glaciology and Geocryology, 31, 301-310, 2009 (in Chinese).

Wang, W., Huang, X. D., Deng, J., Xie, H. J., and Liang, T. G.: Spatio-Temporal Change of Snow Cover and Its Response to Climate over the Tibetan Plateau Based on an Improved Daily Cloud-Free Snow Cover Product, Remote Sens.-Basel, 7, 169194, 2015.
Wu, T. W. and Qian, Z. A.: The relation between the Tibetan winter snow and the Asian summer monsoon and rainfall: An observational investigation, J. Climate, 16, 2038-2051, 2003.

Xu, C. C., Chen, Y. N., and Hamid, Y.: Long-term change of seasonal snow cover and its effects on river runoff in the Tarim River basin, northwestern China, Hydrol. Process., 23, 20452055, 2009.

Xu, X. D., Lu, C. G., Shi, X. H., and Gao, S. T.: World water tower: An atmospheric perspective, Geophys. Res. Lett., 35, L20815, https://doi.org/10.1029/2008GL035867, 2008.

Yang, J. T., Jiang, L. M. M., and Menard, C. B.: Evaluation of snow products over the Tibetan Plateau, Hydrol. Process., 29, 32473260, 2015.

You, Q. L., Kang, S. C., and Ren, G. Y.: Observed changes in snow depth and number of snow days in the eastern and central Tibetan Plateau, Clim. Res., 46, 171-183, 2011.

Yu, Z., Liu, S. R., and Wang, J. X.: Effects of seasonal snow on the growing season of temperate vegetation in China, Glob. Change Biol., 19, 2182-2195, 2013.

Zeng, J. Y., Li, Z., Chen, Q., and Bi, H. Y.: Method for Soil Moisture and Surface Temperature Estimation in the Tibetan Plateau Using Spaceborne Radiometer Observations, IEEE Geosci. Remote S., 12, 97-101, 2015.

Zhang, Y. S., Li, T., and Wang, B.: Decadal change of the spring snow depth over the Tibetan Plateau: The associated circulation and influence on the East Asian summer monsoon, J. Climate, 17, 2780-2793, 2004.

Zhong, X., Zhang, T., and Wang, K.: Snow density climatology across the former USSR, The Cryosphere, 8, 785-799, https://doi.org/10.5194/tc-8-785-2014, 2014. 